\title{
Viral miRNAs Confer Survival in Host Cells by Targeting Apoptosis
}

\section{Related Host Genes}

1 Abstract

2 Background: miRNAs are small non-coding RNAs that regulate the expression of genes by

3 RNA silencing method. Like eukaryotic organisms, some viruses also produce miRNAs. While

4 contribution of host miRNA in the prevention of viral pathogenesis has been studied, it is not

5 known very well how viral miRNA can confer its survival in the host. Here we hypothesized that

6 viral miRNAs can bind to the host target genes to confer their pathogenicity by down-regulating

7 specific pathways and related genes that otherwise pose threat to cell survival.

8 Methods and Results: Using targets of 168 viral miRNAs from 13 different viruses

9 overrepresentation analysis was done. Functional enrichment analysis of the genes targeted by

10 the miRNAs indicates that viruses target specific immune system and host defense related

11 pathways via miRNA mediated gene silencing. Integration and analysis of the publicly available

12 experimental host gene expression data by RNA-seq provided insight that viruses target host

13 apoptosis process by switching off related genes through miRNA induced mechanisms and thus

14 probably ensure their survival.

15 Conclusions: As switching off the apoptosis of host cells would provide the viruses with 16 selective advantages in surviving inside host, our findings therefore envisage an important

17 function of viral miRNA which demands further in vivo experiments for better understanding in

18 this regard.

19 Keywords: miRNA; Viral pathogenesis; Apoptosis; Functional enrichment; Immune system. 


\section{Introduction}

2 miRNAs are $\sim 22$ nucleotide, small, non-coding RNAs that are present in the vertebrates, plants,

3 invertebrates and in a wide range of viruses [1]. The primary function of miRNAs is to regulate

4 the expression of genes post-transcriptionally, via base pair formation with the 3'-Untranslated

5 Region (3'-UTR) of specific messenger RNAs (mRNA). Viral miRNAs play subtle roles in the

6 survival and proliferation of viral particles through host immune system evasion [2], establishing

7 microenvironment for viral replication [3], regulation of innate immune system, differentiation

8 of adaptive immune cells [4] etc.

9 Like most animals and plants, some viruses (mostly DNA viruses), can also produce miRNAs that provide them different selective advantages required for their survival, host immune system evasion, regulation of host and viral genes [5], viral replication [6], influencing viral latency [4], diminishing host antiviral responses, suppressing host cell apoptosis [5] etc. Initially, viral miRNAs were found in the Epstein-Barr virus [7] but later on other viral families like,

14 Herpesvirus, Polyomavirus, Ascovirus, Iridovirus, Baculovirus, Adenovirus, Retrovirus [8] etc. were also found to produce miRNAs [9]. At present more than 20 human viruses are expected to 16 produce miRNAs, among which almost 10-12 are already validated experimentally. These 17 human viruses produce almost about 135 miRNAs [10], which are thought to be beneficial for 18 the viruses to survive in human bodies.

19 These viruses produce miRNAs that can control the expression of the corresponding viral genes

20 and some human genes as well. The miRNA sequences found from these viruses have been

21 analyzed and their respective target sites have been found at the 3'-UTR regions of many genes

22 in human [10]. It is expected that these miRNAs may provide some selective advantages to the 
1 viruses so that they can evade the host defense machineries. Since viruses need to replicate inside

2 host cell, they may need to take necessary initiative to prevent host cell death by apoptosis and

3 other immunologic mechanisms. That is why, we hypothesized that viral miRNAs may down

4 regulate apoptosis by targeting apoptosis related genes, thereby they ensure prolonged survival

5 of the host cells as well as themselves.

\section{2. Materials and Methods}

\section{$7 \quad$ 2.1. Identification of Viral miRNAs and their Target Genes}

8 To understand the functions of viral miRNAs in providing selective advantages to the viruses,

9 first it was required to know the viruses which produce the miRNAs. For this purpose miRbase

10 [11] was explored and the human viruses that produce miRNAs were identified. From miRBase

11 mature FASTA sequences of the viral miRNAs were also extracted for further analyses. Using

12 the target identifying tools TargetScan [12], RNAhybrid [13] and PITA [14] we scanned the 3'-

13 UTR regions of the human protein coding genes for putative binding of miRNAs and from

14 databases UTRdb [15], miRTarBase [16] that house target genes of viral miRNAs we obtained

15 the putative and experimentally validated target gene sequences, gene symbols etc. Target genes

16 obtained from these databases and targets that we identify by scanning UTRs were combined to

17 make a unique union set of viral miRNA targets.

\subsection{Functional Enrichment Analysis}

19 To annotate functions of all the genes we obtained the Biological Processes (GOBP), Cellular 
1 (GO) $[17,18]$. The pathways involved were obtained from Kyoto Encyclopedia of Genes and

2 Genomes (KEGG) [19]. In both cases Ensembl genes (Release 79: March, 2015) [20] were used.

3 We used Gitools [21] (Version: 1.8.4) to perform enrichment analysis and to generate heatmaps

4 using the targeted biological processes or pathways and the corresponding p-values. The Right P-

5 value was used as the parameter. Genes associated with the biological processes and pathways

6 can be viewed and thereby the target genes in each biological process or pathway can be

7 observed.

\subsection{Gene Expression Microarray Data Analysis}

9 Gene Expression Omnibus (GEO) [22] is a curated, public reservoir of microarray gene 10 expression data at National Center for Biological Information (NCBI). From GEO, we used the 11 RNA-seq dataset GSE44769 which used the platform Illumina Genome Analyzer IIx 12 (GPL10999). In this particular dataset, the experiment was done using Epstein-Barr virus (EBV) 13 cell line in four different conditions including "No BART, EtOH”, "BART, Dox", "No BART, 14 Dox" and "Dox, EtOH" to obtain the expression of genes in those conditions. The data of "No 15 BART, EtOH" was taken as the control of this dataset and the data of "BART, Dox" was taken 16 as the most appropriate sample. Using in house $\mathrm{R}$ script the data were converted into $\log 2$ 17 values from absolute expression and the differential expression level of the genes in the experimental condition were identified comparing with the control.

“Apoptosis" related gene set was extracted from KEGG database "apoptosis pathway" terms and

20 the expressions of those genes were obtained from the RNA-seq data. Apoptotic genes which

21 were down-regulated more than two folds were taken in consideration to identify viral miRNAs 22 targeting them. We studied the functions of these significantly down-regulated genes to learn 
1 about the selective advantages that the miRNAs can provide the viruses by knocking down these

2 genes. Overview of the complete research is summarized in Figure-1.

\section{Result}

\subsection{From 13 Human viruses 168 miRNAs and their targets were retrieved from various databases}

From miRbase and various publications [4, 5, 7, 10, 23-27], miRNAs of the human viruses were obtained. Among these viruses, 13 human viruses were chosen whose putative miRNAs were already published (Additional File-1). There were 168 miRNAs observed from these 13 viruses. Taking these viral miRNAs with their sequences obtained from miRBase, target genes in human genome were identified from the databases RNAhybrid [13], miRTarBase [16] and from the online software PITA [14] and TargetScan [12]. A union set of target genes was created combining all the obtained target genes from the databases and tools. There were almost 22,000 unique genes observed which were targeted by the viral miRNAs, among which, EBV targeted about 16,000 genes, HIV, HBV, HSV1, HSV2, KSHV and HCMV targeted about 15,000 genes, BKV, JCV and MCV targeted about 7,000 genes.

\subsection{Functional enrichment analysis shows clusters of over-expressed pathways and biological processes}

Enrichment analysis is performed to evaluate the statistical significance of biological conditions and to identify whether particular sets of biological processes are targeted in an increased proportion. The biological processes and KEGG pathways which were significantly enriched 
1 were taken into consideration for preparing different clusters. The cut-off value for the

2 significance was set to FDR corrected P-value 0.05 (Figure-2).

3 By studying various experiments and related articles several important KEGG pathways and

4 associated biological processes were identified which were clustered together and selected for

5 further analyses. The selected pathways were: Calcium mediated signaling, MAPK cascade, Wnt

$6 \quad$ signaling pathway and Apoptosis (Figure-3).

7 3.3. Enrichment analysis of Apoptosis provided 84 enriched genes targeted by viral miRNAs

9 Enrichment analysis provided us the enriched biological processes related to apoptosis. We then identified the annotated enriched genes of the apoptosis process from KEGG pathway in Gitools.

11 There were 84 enriched genes (corrected p-value $<0.05$ ) observed which were targeted by the

12 viral miRNAs. Enriched apoptosis related genes were retrieved and represented in a color coded 13 heatmap (Figure-4).

\subsection{Microarray analysis of EBV cell line provided significant downregulation of 49 genes} associated with Apoptosis genes that showed deviated expression level compared to the control condition. Among these 75 that viral miRNA would down-regulate apoptosis process, we selected the genes which were 
1 After getting the down regulated genes from the RNA-seq we assigned the miRNAs of EBV to

2 their corresponding target genes with their expression levels. We found out that there were

3 several miRNAs which targeted same apoptosis gene (Additional File-2).

\subsection{Functions of the 20 most significantly downregulated apoptosis genes provided insight about the reason of miRNAs targeting them}

As soon as the EBV miRNAs were assigned with their corresponding apoptosis genes, the most significantly down regulated apoptosis genes were identified from the total genes in the Microarray data taking the bottom 20\% expressed genes ( $\log 2$ ratio $<-2.74)$. There were 20 apoptosis genes observed which were most significantly down regulated (Additional File-2). Functions of these genes were studied from UniProt $[28,29]$ protein database to learn about the reason of miRNAs targeting them (Table-1).

\section{Discussion}

miRNAs have become an important subject of interest in recent years in the fields of molecular biology. Their roles in regulating gene expression have become something of remarkable importance to learn about the functions of particular genes and their encoded products. Various organisms including vertebrates, invertebrates [1], plants [1], viruses etc. produce miRNAs to regulate the expression of their genes, thereby controlling their physiological functions. At present there are more than 9000 miRNA genes annotated among which about 700 miRNA genes are from humans [30]. These miRNAs have various roles to ensure proper homeostatic conditions of an organism. One such role includes the host-pathogen relationship. 
1 It is already established in various experimental works that human miRNAs target viral genes

$2[31,32]$ and function as antiviral mediators to suppress viral pathogenesis. By silencing the

3 disease-causing genes of a virus human miRNAs ensure the prevention of any deleterious events

4 caused by that virus. On the contrary there are very little evidences to prove that viral miRNAs

5 effectively target and regulate host genes. Pathogenic viruses cause several diseases in human

6 and human defense machineries continuously encounter and remove these pathogenic viruses

7 from the system. To evade these host defense molecules viruses might have further evolved to

8 produce miRNAs to silence host genes. This silencing can provide them with various selective

9 advantages including host defense evasion, viral replication [5], diminishing antiviral responses etc. To accentuate this event whether viruses effectively target and control host genes we

11 proceeded with several scientific works from different laboratories and gained insight about the role of viral miRNAs in their own survival.

After performing enrichment analysis, we observed that various physiological processes are enriched at a high level. We clustered these pathways and found viruses target biological processes like immune system related pathways, Wnt pathway, MAP Kinase cascade, apoptosis etc. at a significantly high level through their miRNAs. We predicted that switching these pathways off may serve them some selective advantage in their survival inside human host. So,

18 we studied about these pathways and other related findings.

19 Carl et al. [10] worked with several viruses and associated miRNAs to hypothesize that viral 20 miRNAs target host pathways by regulating the host gene expressions. They looked for the 21 predicted miRNAs from different databases and tried to find the target genes. Then they obtained 22 the enriched GO biological processes and predicted that viral miRNAs target some pathways. 23 Their major drawback was that they failed to provide any experimentally validated proof in these 
1 regards. We identified the pathways and their corresponding genes targeted by viral miRNAs

2 which were further verified by using RNA-seq datasets of Vereide et al. [33] who worked with

3 miRNAs of Epstein-Barr virus and found that some EBV miRNAs are responsible for the

4 transformation of B lymphocytes in Burkitt's Lymphoma. We are providing here proof that viral

5 miRNAs do target human genes and control specific pathways, like apoptosis.

6 Apoptosis is a natural physiological phenomenon where cells undergo programmed death when

7 they reach maturity or are infected by any pathogen [34-36]. This process is very important to

8 maintain homeostasis of an organism. Apoptosis prevents various deleterious effects like the

9 progression of viral pathogenesis, cancer etc. As we have already found that viral miRNAs target host genes for their own survival, we predicted that viruses may specifically target and regulate host apoptosis process so that they can ensure their refuge and prolonged survival in host cells. Bearing this context in mind, we searched for the most significantly targeted genes by viral miRNAs and found that there are several host genes related to apoptosis which are downregulated at a very significantly high level. These findings strengthened our hypothesis about viruses selectively targeting host apoptosis pathway for their own survival.

There are several viruses that cause various deleterious effects in humans. One such diseasecausing virus is EBV, which is also called Human Herpesvirus-4 (HHV-4). EBV is the causative agent of a common disease named Infectious mononucleosis or simply Mono. But it can also cause several forms of cancer including Hodgkin's lymphoma, Burkitt's lymphoma, gastric cancer, nasopharyngeal carcinoma etc. There are several evidences showing that EBV is

21 associated with some autoimmune diseases as well [37]. Despite causing so much adverse effects

22 in human very less information is known about the complete pathogenesis of EBV inside host 
1 system. To gather insight about the pathogenesis of this particular virus we predicted that their

2 pathogenesis may involve silencing the genes of the hosts via miRNAs.

3 Pfeffer et al. [38] published their scientific findings about the miRNAs of the viruses that belong

4 to the Herpesvirus family. They performed computational methods to predict pre-miRNAs and

5 then experimentally obtained the miRNAs produced by these viruses. We further worked with

6 the miRNAs specially those of EBV and obtained their target genes. As mentioned earlier, we

7 found several apoptosis related genes that are significantly controlled by EBV miRNAs. That

8 accentuates the fact that one of the ways of viral pathogenesis includes miRNA mediated gene

9 silencing. We studied the functions of the apoptosis related genes that are highly knocked down

10 by viral miRNAs and found that most of them are associated with controlling apoptosis by

11 positively influencing the process. Thus, it results in continued survival of the host cells and

12 provides prolonged refuge to the viral particles when these genes are silenced by viral miRNAs.

13 Genes like $B A D, C A S P 9, B I D$ etc. are associated with the induction of apoptosis in human,

14 which are highly targeted by viral miRNAs. Observing the experimentally validated expression

15 levels of these genes after introduction of viral miRNAs we predict that viruses selectively target

16 these genes that positively control apoptosis and switch them off by producing specific miRNAs.

17 miRNAs are emerging to be important molecules in the fields of molecular biology, genetic

18 engineering etc. It is gaining emphasis in the sectors of understanding the functions of genes and

19 gene products. We can further experiment with these miRNAs to learn more about the host-

20 pathogen interactions and combat the emerging pathogens. Diseases that are yet to be overcome

21 due to lack of knowledge can be fought against with the knowledge of miRNA-gene interactions.

\section{4. Conclusion}


1 The role of miRNAs in regulating gene expression has become a significant aspect scientific

2 interest recently. Here, we showed the role of miRNAs in the establishment of viruses inside the

3 human hosts through controlling the apoptosis process and ensuring their prolonged refuge. This

4 finding can be further strengthened by in vivo experiments that would result in better

5 understanding in this context.

\section{$6 \quad$ List of Abbreviations}

7 miRNA: microRNA; UTR: Untranslated region; DNA: Deoxyribonucleic acid; GO: Gene

8 Ontology; BP: Biological processes; CL: Cellular locations; MF: Molecular functions; KEGG:

9 Kyoto Encyclopedia of Genes and Genomes; GEO: Gene Expression Omnibus; HIV: Human

10 Immunodeficiency virus; EBV: Epstein-Barr virus; HBV: Hepatitis B virus; HSV: Herpes

11 Simplex virus; KSHV: Kaposi's Sarcoma-associated Herpesvirus; HCMV: Human

12 Cytomegalovirus; BKV: BK Polyomavirus; JCV: JC Polyomavirus; MCV: Merkel Cell

13 Polyomavirus; FDR: False discovery rate.

\section{Acknowledgements}

15 We acknowledge our gratitude for the research support by the Department of Genetic 16 Engineering and Biotechnology, University of Dhaka.

\section{Availability of Data and Materials}

18 The datasets supporting the conclusions of this article are included in the article and in the 19 additional files.

\section{$20 \quad$ Funding}

21 The project was not funded by any organization. 


\section{References}

1. $\quad$ Ding S-W, Voinnet O: Antiviral Immunity Directed by Small RNAs. Cell 2007, 130(3):413426.

2. Stern-Ginossar N, Elefant N, Zimmermann A, Wolf DG, Saleh N, Biton M, Horwitz E, Prokocimer Z, Prichard M, Hahn G et al: Host Immune System Gene Targeting by a Viral miRNA. Science (New York, NY) 2007, 317(5836):376-381.

3. Skalsky RL, Cullen BR: Viruses, microRNAs, and Host Interactions. Annual review of microbiology 2010, 64:123-141.

4. Kincaid RP, Sullivan CS: Virus-encoded microRNAs: an overview and a look to the future. PLoS Pathog 2012, 8(12):e1003018.

5. Nukui M, Mori Y, Murphy EA: A Human herpesvirus 6A encoded miRNA: A role in viral lytic replication. Journal of Virology 2014.

6. Zhang Y, Fan M, Geng G, Liu B, Huang Z, Luo H, Zhou J, Guo X, Cai W, Zhang H: A novel HIV-1-encoded microRNA enhances its viral replication by targeting the TATA box region. Retrovirology 2014, 11:23.

7. Pfeffer S, Zavolan M, Grässer FA, Chien M, Russo JJ, Ju J, John B, Enright AJ, Marks D, Sander C et al: Identification of Virus-Encoded MicroRNAs. Science 2004, 304(5671):734-736.

8. Kincaid RP, Burke JM, Cox JC, de Villiers EM, Sullivan CS: A human torque teno virus encodes a microRNA that inhibits interferon signaling. PLoS Pathog 2013, 9(12):e1003818.

9. Islam MS, Khan MA, Murad MW, Karim M, Islam A: In silico analysis revealed Zika virus miRNAs associated with viral pathogenesis through alteration of host genes involved in immune response and neurological functions. Journal of medical virology 2019, 91(9):15841594.

10. Carl JW, Jr., Trgovcich J, Hannenhalli S: Widespread evidence of viral miRNAs targeting host pathways. BMC bioinformatics 2013, 14 Suppl 2:S3.

11. Griffiths-Jones S, Saini HK, van Dongen S, Enright AJ: miRBase: tools for microRNA genomics. Nucleic Acids Research 2008, 36(suppl 1):D154-D158.

12. Agarwal V, Bell GW, Nam JW, Bartel DP: Predicting effective microRNA target sites in mammalian mRNAs. eLife 2015, 4.

13. Kruger J, Rehmsmeier M: RNAhybrid: microRNA target prediction easy, fast and flexible. Nucleic Acids Res 2006, 34(Web Server issue):W451-454.

14. Kertesz M, Iovino N, Unnerstall U, Gaul U, Segal E: The role of site accessibility in microRNA target recognition. Nature genetics 2007, 39(10):1278-1284.

15. Grillo G, Turi A, Licciulli F, Mignone F, Liuni S, Banfi S, Gennarino VA, Horner DS, Pavesi G, Picardi E et al: UTRdb and UTRsite (RELEASE 2010): a collection of sequences and regulatory motifs of the untranslated regions of eukaryotic mRNAs. Nucleic Acids Res 2010, 38(Database issue):D75-80.

16. Hsu SD, Tseng YT, Shrestha S, Lin YL, Khaleel A, Chou CH, Chu CF, Huang HY, Lin CM, Ho SY et al: miRTarBase update 2014: an information resource for experimentally validated miRNA-target interactions. Nucleic Acids Res 2014, 42(Database issue):D78-85.

17. Ashburner M, Ball CA, Blake JA, Botstein D, Butler H, Cherry JM, Davis AP, Dolinski K, Dwight SS, Eppig JT et al: Gene Ontology: tool for the unification of biology. Nat Genet 2000, 25(1):25-29.

18. Consortium TGO: Gene Ontology Consortium: going forward. Nucleic Acids Research 2015, 43(D1):D1049-D1056.

19. Kanehisa M, Araki M, Goto S, Hattori M, Hirakawa M, Itoh M, Katayama T, Kawashima S, Okuda S, Tokimatsu T et al: KEGG for linking genomes to life and the environment. Nucleic Acids Res 2008, 36(Database issue):D480-484. 


\footnotetext{
20. Cunningham F, Amode MR, Barrell D, Beal K, Billis K, Brent S, Carvalho-Silva D, Clapham P, Coates G, Fitzgerald S et al: Ensembl 2015. Nucleic Acids Research 2015, 43(D1):D662-D669.

21. Perez-Llamas C, Lopez-Bigas N: Gitools: analysis and visualisation of genomic data using interactive heat-maps. PLoS One 2011, 6(5):e19541.

22. Barrett T, Wilhite SE, Ledoux P, Evangelista C, Kim IF, Tomashevsky M, Marshall KA, Phillippy KH, Sherman PM, Holko M et al: NCBI GEO: archive for functional genomics data sets--update. Nucleic Acids Res 2013, 41(Database issue):D991-995.

23. Yu G, He QY: Functional similarity analysis of human virus-encoded miRNAs. Journal of clinical bioinformatics 2011, 1(1):15.

24. You X, Zhang Z, Fan J, Cui Z, Zhang XE: Functionally orthologous viral and cellular microRNAs studied by a novel dual-fluorescent reporter system. PLoS One 2012, 7(4):e36157.

25. Seo GJ, Fink LHL, O'Hara B, Atwood WJ, Sullivan CS: Evolutionarily Conserved Function of a Viral MicroRNA. Journal of Virology 2008, 82(20):9823-9828.

26. Gottwein E, Mukherjee N, Sachse C, Frenzel C, Majoros WH, Chi J-TA, Braich R, Manoharan $\mathrm{M}$, Soutschek J, Ohler $\mathrm{U}$ et al: A viral microRNA functions as an orthologue of cellular miR155. Nature 2007, 450(7172):1096-1099.

27. Cai X, Lu S, Zhang Z, Gonzalez CM, Damania B, Cullen BR: Kaposi's sarcoma-associated herpesvirus expresses an array of viral microRNAs in latently infected cells. Proc Natl Acad Sci U S A 2005, 102(15):5570-5575.

28. UniProt: a hub for protein information. Nucleic Acids Res 2015, 43(Database issue):D204212.

29. Wu CH, Apweiler R, Bairoch A, Natale DA, Barker WC, Boeckmann B, Ferro S, Gasteiger E, Huang H, Lopez R et al: The Universal Protein Resource (UniProt): an expanding universe of protein information. Nucleic Acids Res 2006, 34(Database issue):D187-191.

30. Ghosh Z, Mallick B, Chakrabarti J: Cellular versus viral microRNAs in host-virus interaction. Nucleic Acids Research 2009, 37(4):1035-1048.

31. Jopling CL, Yi M, Lancaster AM, Lemon SM, Sarnow P: Modulation of hepatitis C virus RNA abundance by a liver-specific MicroRNA. Science 2005, 309(5740):1577-1581.

32. Hariharan M, Scaria V, Pillai B, Brahmachari SK: Targets for human encoded microRNAs in HIV genes. Biochem Biophys Res Commun 2005, 337(4):1214-1218.

33. Vereide DT, Seto E, Chiu YF, Hayes M, Tagawa T, Grundhoff A, Hammerschmidt W, Sugden B: Epstein-Barr virus maintains lymphomas via its miRNAs. Oncogene 2014, 33(10):1258-1264.

34. Elmore S: Apoptosis: A Review of Programmed Cell Death. Toxicologic pathology 2007, 35(4):495-516.

35. Horvitz HR: Genetic control of programmed cell death in the nematode Caenorhabditis elegans. Cancer research 1999, 59(7 Suppl):1701s-1706s.

36. Kroemer G, Galluzzi L, Vandenabeele P, Abrams J, Alnemri ES, Baehrecke EH, Blagosklonny MV, El-Deiry WS, Golstein P, Green DR et al: Classification of cell death: recommendations of the Nomenclature Committee on Cell Death 2009. Cell death and differentiation 2009, 16(1):3-11.

37. Toussirot E, Roudier J: Epstein-Barr virus in autoimmune diseases. Best practice \& research Clinical rheumatology 2008, 22(5):883-896.

38. Pfeffer S, Sewer A, Lagos-Quintana M, Sheridan R, Sander C, Grasser FA, van Dyk LF, Ho CK, Shuman S, Chien $\mathrm{M}$ et al: Identification of microRNAs of the herpesvirus family. Nature methods 2005, 2(4):269-276.
}

\section{Figure Legends}

Figure-1: Schematic diagram summarizing the study 
Figure-2: Enrichment of gene ontology biological processes: Representation of (selected) GOBP

2 (Immune system) enriched terms related to immune system obtained from Gitools. Statistical significance

3 (FDR corrected p-values) is represented in a color coded scale. Color towards red indicates more

4 significant and color towards yellow means less significant, and gray color indicates non-significance (>

$50.05)$.

6 Figure-3: Enrichment analysis of pathways: Overrepresentation of Biological processes of (A) MAPK

7 cascade, (B) Wnt signaling pathway, (C) calcium mediated signaling, (D) Apoptosis obtained from

8 Gitools. Color scale and legend as in Figure 2.

$9 \quad$ Figure-4: Enriched apoptosis genes targeted by viral miRNAs: Enriched genes related to apoptosis

10 process obtained from Gitools. The Blue colored hits express the genes that are targeted by viral miRNAs

11 and the Gray colored hits are the genes that are not targeted by viral miRNAs. Vertical lines express viral

12 miRNAs and the horizontal lines express corresponding target genes.

Figure-5: Expression level of the down-regulated genes: Down-regulated genes are represented in a color coded scale based on their expression level. The genes that are down-regulated at least two-fold

15 (Log2 ratio $<-0.5)$ are considered. The significance level of down-regulation is taken at -1.5 of the $\log 2$ ratio, which is represented as White color. Genes having Log2 ratios less than -1.5 are represented as

17 Green color and genes having values more than -1.5 are represented as Blue color.

Tables

Table-1: Functions of most significantly down regulated genes obtained from UniProt

\begin{tabular}{|c|l|l|l|}
\hline Serial & Gene Symbol & \multicolumn{1}{|c|}{ Encoded Protein } & \multicolumn{2}{|c|}{ Function } \\
\hline \multirow{2}{*}{1.} & $B A D$ & Bcl2-associated & Promotes cell death. It has cysteine-type \\
endopeptidase activator activity, which is \\
\end{tabular}




\begin{tabular}{|c|c|c|c|}
\hline 2. & AKT3 & $\begin{array}{l}\text { RAC-gamma } \\
\text { serine/threonine- } \\
\text { protein kinase }\end{array}$ & $\begin{array}{l}\text { Regulates metabolism, cellular proliferation, cell } \\
\text { survival, growth and angiogenesis. }\end{array}$ \\
\hline 3. & $I L I A$ & Interleukin-1 alpha & $\begin{array}{l}\text { Involved in the inflammatory response. Can } \\
\text { stimulate the release of prostaglandin and } \\
\text { collagenase from synovial cells. }\end{array}$ \\
\hline 4. & $R E L A$ & $\begin{array}{l}\text { Transcription factor } \\
\text { p65, RELA protein }\end{array}$ & $\begin{array}{l}\text { Involved in } \mathrm{NF}_{\mathrm{K}} \mathrm{B} \text { heterodimer formation, nuclear } \\
\text { translocation and activation. }\end{array}$ \\
\hline 5. & AIFMI & $\begin{array}{l}\text { Apoptosis-inducing } \\
\text { factor } 1, \text { mitochondrial }\end{array}$ & $\begin{array}{l}\text { Functions as an NADH oxidoreductase and } \\
\text { regulates apoptosis. Acts as a proapoptotic factor } \\
\text { in a caspase-indipendent pathway when released } \\
\text { into cytosol and nucleus from the mitochondria. }\end{array}$ \\
\hline 6. & CAPN1 & $\begin{array}{l}\text { Calpain-1 catalytic } \\
\text { subunit }\end{array}$ & $\begin{array}{l}\text { Catalyzes limited proteolysis of substrates } \\
\text { involved in cytoskeletal remodeling and signal } \\
\text { transduction. }\end{array}$ \\
\hline 7. & PRKACA & $\begin{array}{l}\text { cAMP-dependent } \\
\text { protein kinase } \\
\text { catalytic subunit alpha }\end{array}$ & $\begin{array}{l}\text { Subunit of Protein Kinase A, which regulates } \\
\text { glucose metabolism, cell division etc. PKA } \\
\text { phosphorylates other proteins, thereby changing } \\
\text { their activities. }\end{array}$ \\
\hline 8. & PRKARIB & $\begin{array}{l}\text { cAMP-dependent } \\
\text { protein kinase type I- } \\
\text { beta regulatory subunit }\end{array}$ & $\begin{array}{l}\text { Regulatory subunit of cAMP-dependent protein } \\
\text { kinases that are involved in cAMP signaling in } \\
\text { cells. }\end{array}$ \\
\hline 9. & РРРЗСС & $\begin{array}{l}\text { Serine/threonine- } \\
\text { protein phosphatase } \\
\text { 2B catalytic subunit } \\
\text { gamma isoform }\end{array}$ & $\begin{array}{l}\text { Calcium dependent, calmodulin stimulated protein } \\
\text { phosphatase, which has a role in calmodulin } \\
\text { activation in calcineurin. }\end{array}$ \\
\hline 10. & $T R A D D$ & $\begin{array}{l}\text { Tumor necrosis factor } \\
\text { receptor type } 1 \text { - }\end{array}$ & $\begin{array}{l}\text { Acts as a tumor suppressor by preventing } \\
\text { ubiquitination. It's over expression leads to }\end{array}$ \\
\hline
\end{tabular}




\begin{tabular}{|c|c|c|c|}
\hline & & $\begin{array}{l}\text { associated DEATH } \\
\text { domain protein }\end{array}$ & apoptosis and $\mathrm{NF}_{\mathrm{K}} \mathrm{B}$ activation. \\
\hline 11. & CASP9 & Caspase-9 & Involved in apoptosis. \\
\hline 12. & $B I D$ & $\begin{array}{l}\text { BH3-interacting } \\
\text { domain death agonist }\end{array}$ & $\begin{array}{l}\text { Induces apoptosis. It is a major proteolytic } \\
\text { product, which releases cytochrome c. }\end{array}$ \\
\hline 13. & $I L I B$ & Interleukin-1 beta & $\begin{array}{l}\text { It is a proinflammatory cytokine which induces } \\
\text { prostaglandin synthesis, neutrophil influx and } \\
\text { activation, T-cell activation and cytokine } \\
\text { production, B-cell activation and antibody } \\
\text { production, and fibroblast proliferation and } \\
\text { collagen production. }\end{array}$ \\
\hline 14. & $A K T 1$ & $\begin{array}{l}\text { RAC-alpha } \\
\text { serine/threonine- } \\
\text { protein kinase }\end{array}$ & $\begin{array}{l}\text { It regulates cell survival via the phosphorylation } \\
\text { of MAP3K5 (apoptosis signal-related kinase). Has } \\
\text { an important role in the regulation of } \mathrm{NF}_{\mathrm{K}} \mathrm{B} \text { - } \\
\text { dependent gene transcription and positively } \\
\text { regulates the activity of CREB1 (cAMP-response } \\
\text { element binding protein). The phosphorylation of } \\
\text { CREB1 induces the binding of accessory proteins } \\
\text { that are necessary for the transcription of pro- } \\
\text { survival genes such as BCL } 2 \text { and MCL1. }\end{array}$ \\
\hline 15. & $P R K A R 2 B$ & $\begin{array}{l}\text { cAMP-dependent } \\
\text { protein kinase type II- } \\
\text { beta regulatory subunit }\end{array}$ & $\begin{array}{l}\text { Mediates membrane association by binding to } \\
\text { anchoring proteins, like MAP2 kinase. }\end{array}$ \\
\hline 16. & $B C L 2 L 1$ & Bcl-2-like protein 1 & $\begin{array}{l}\text { Prevents apoptosis by inhibiting caspases. } \\
\text { Regulates cell death by blocking the voltage- } \\
\text { dependent anion channel (VDAC) by binding to it } \\
\text { and preventing the release of the caspase } \\
\text { activator, CYC1, from the mitochondrial }\end{array}$ \\
\hline
\end{tabular}




\begin{tabular}{|c|c|c|c|}
\hline & & & $\begin{array}{l}\text { membrane. Also acts as a regulator of } \mathrm{G} 2 \\
\text { checkpoint and progression to cytokinesis during } \\
\text { mitosis. }\end{array}$ \\
\hline 17. & $P I K 3 R 2$ & $\begin{array}{l}\text { Phosphatidylinositol } \\
\text { 3-kinase regulatory } \\
\text { subunit beta }\end{array}$ & $\begin{array}{l}\text { Phosphorylates Phosphatidylinositol 4,5- } \\
\text { bisphosphate to generate } \mathrm{PIP}_{3} \\
\text { (phosphatidylinositol 3,4,5-trisphosphate). } \mathrm{PIP}_{3} \\
\text { plays a key role in activating signaling cascades } \\
\text { involved in cell growth, survival, proliferation, } \\
\text { motility and morphology. }\end{array}$ \\
\hline 18. & ENDOG & $\begin{array}{l}\text { Endonuclease G, } \\
\text { mitochondrial }\end{array}$ & $\begin{array}{l}\text { Cleaves DNA at specific sites. Also has an RNase } \\
\text { and RNase } \mathrm{H} \text { activity. Can generate primers } \\
\text { during mitochondrial DNA replication. }\end{array}$ \\
\hline 19. & $I K B K G$ & $\begin{array}{l}\mathrm{NF}_{\mathrm{K}} \mathrm{B} \text { essential } \\
\text { modulator }\end{array}$ & $\begin{array}{l}\text { Essential for viral activation of IRF3. Involved in } \\
\text { TLR3- and IFIH1-mediated antiviral innate } \\
\text { response. }\end{array}$ \\
\hline 20. & $B A X$ & $\begin{array}{l}\text { Apoptosis regulator } \\
\text { BAX }\end{array}$ & $\begin{array}{l}\text { Accelerates Apoptosis by binding and repressing } \\
\text { BCL2, activating CASP3, and releasing } \\
\text { cytochrome c from mitochondria. }\end{array}$ \\
\hline
\end{tabular}

\section{Additional Files}

\section{Additional File-1:}

- Title of data: Human viruses with miRNAs

- File format: Microsoft Word Document

- Description of data: Provides information about the human viruses that produce miRNAs

\section{Additional File-2:}

- Title of data: miRNAs of EBV and their target genes with expression levels

- File format: Microsoft Word Document

- Description of data: Provides information about the miRNAs produced by EBV and the genes targeted by them 


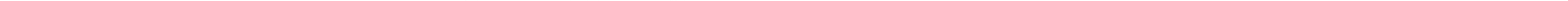




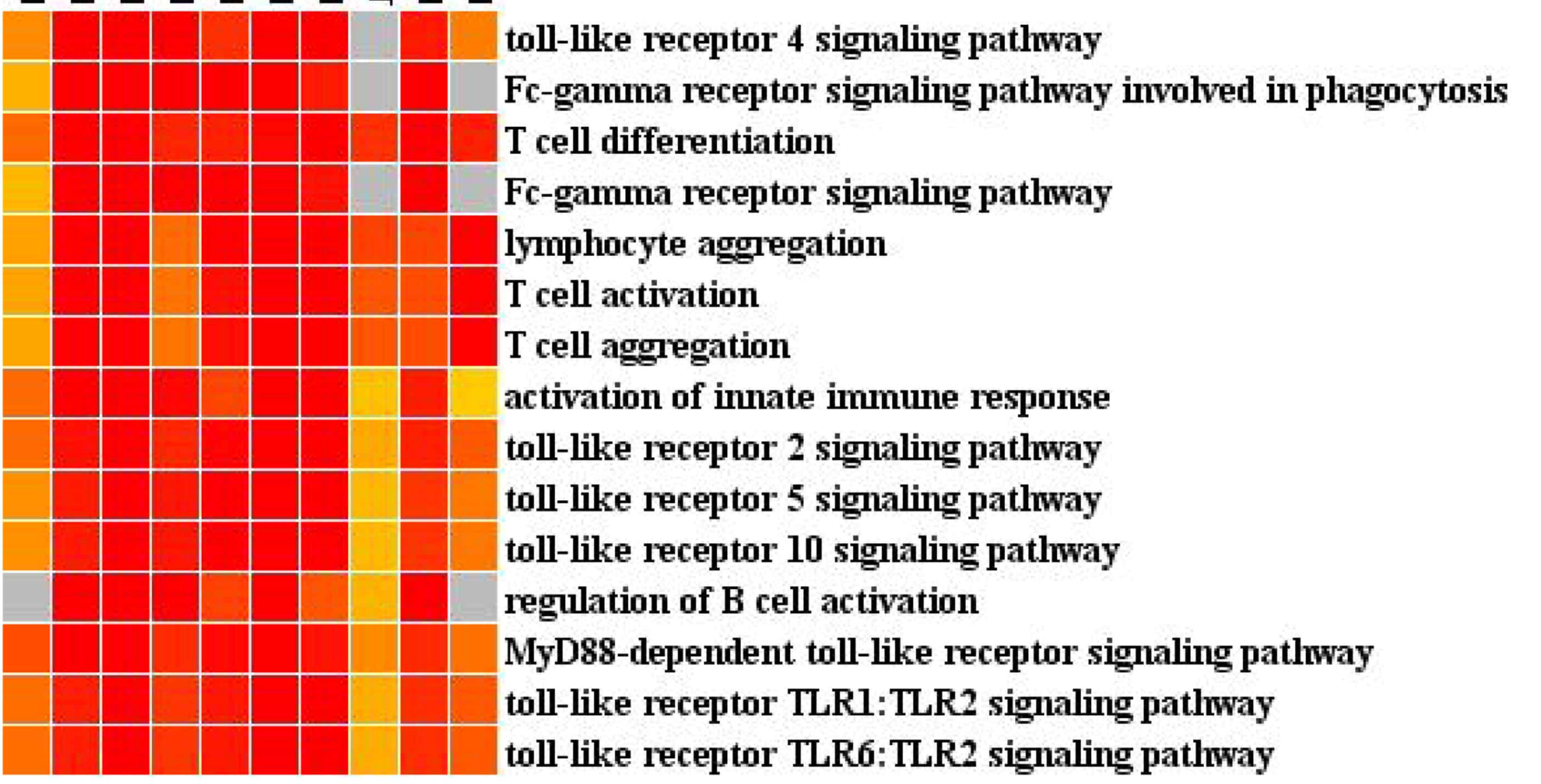


(A)

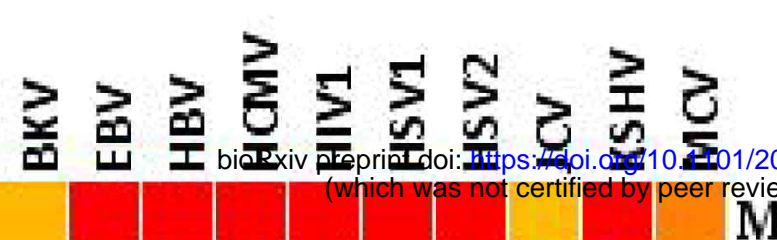

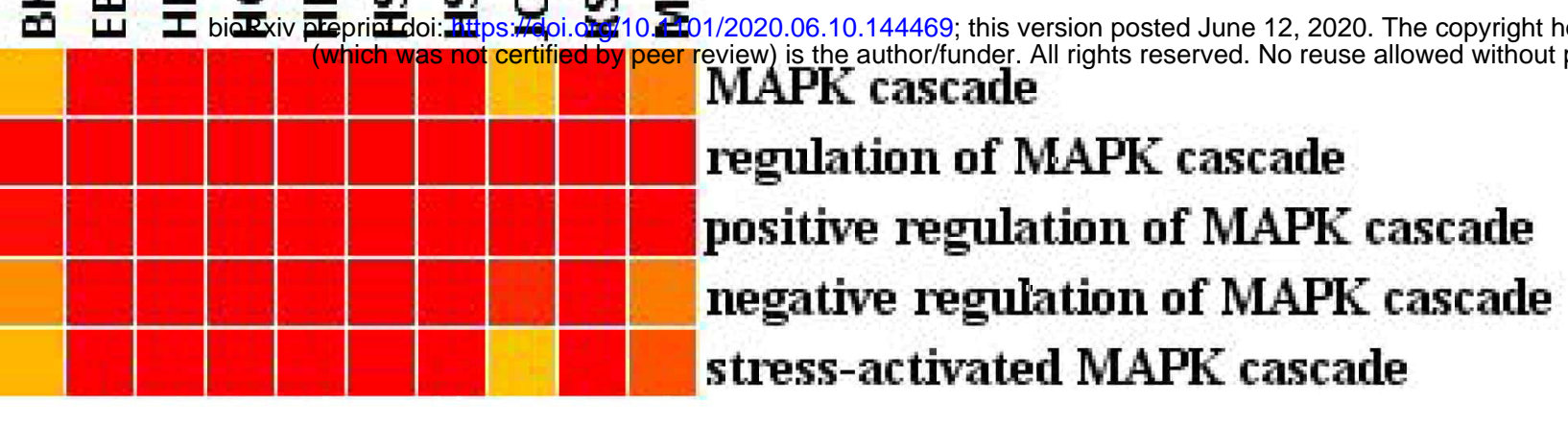

(B)

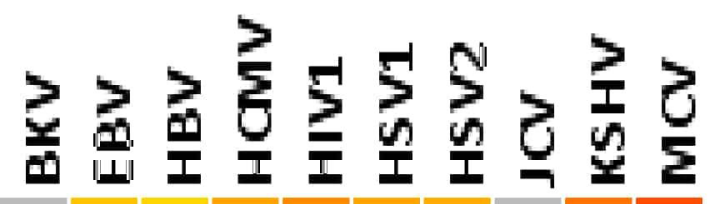

calcium-mediated signaling

regulation of calcium-mediated signaling

regulation of cardiac muscle contraction by calcium ion signaling

regulation of cardiac muscle contraction by regulation of the release of sequestered calcium ion

(C)

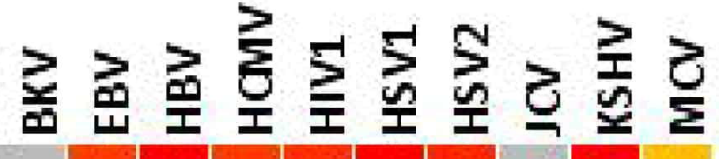

\begin{tabular}{|l|l|l|l} 
& canonical Wnt signaling pathway \\
Wnt signaling pathway \\
non-canonical Wnt signaling pathway \\
regulation of Wnt signaling pathway \\
negative regulation of canonical Wnt signaling pathway \\
Wnt signaling pathway, planar cell polarity pathway \\
\\
& negative regulation of Wnt signaling pathway \\
& positive regulation of Wnt signaling pathway \\
& regulation of canonical Wnt signaling pathway \\
& regulation of Wnt signaling pathway, planar cell polarity pathway \\
& planar cell polarity pathway involved in neural tube closure
\end{tabular}

Significant

Non-Significant

1

1

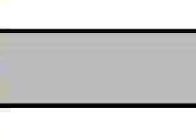

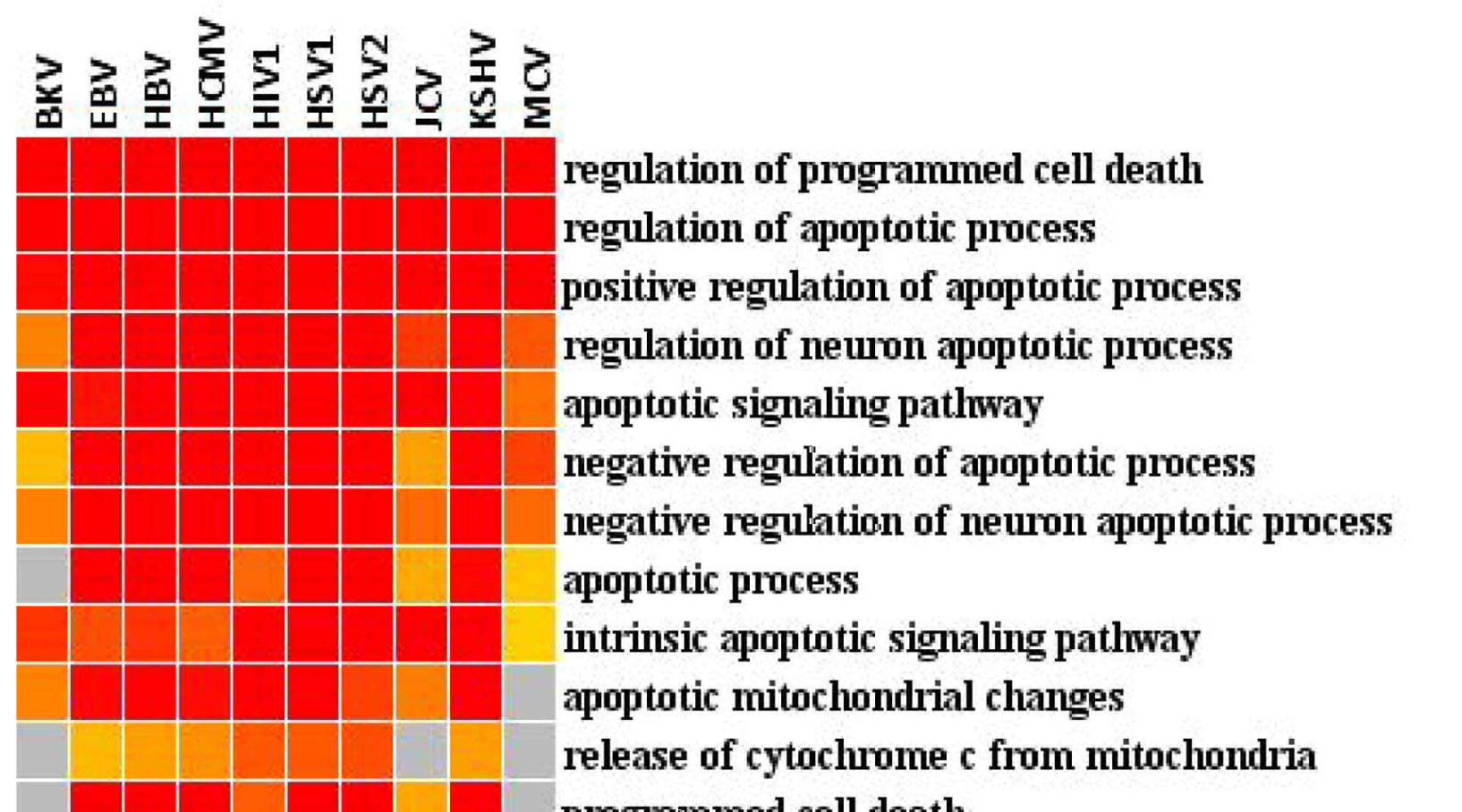

release of cytochrome $c$ from mitochondria

programmed cell death

regulation of mitochondrial membrane permeability involved in apoptotic process

regulation of extrinsic apoptotic signaling pathway

regulation of cysteine-type endopeptidase activity involved in apoptotic process

positive regulation of extrinsic apoptotic signaling pathway

positive regulation of intrinsic apoptotic signaling pathway

positive regulation of neuron apoptotic process

regulation of intrinsic apoptotic siogaling pathway

neuron apoptotic process

neuron apoptotic process
extrinsic apoptotic signaling pathway

extrinsic apoptotic signaling pathway
cellular component disassembly involved in execution phase of apoptosis

regulation of anoikis

regulation of execution phase of apoptosis

regulation of extrinsic apoptotic signaling pathway via death domain receptors

(D)

positive regulation of extrinsic apoptotic signaling pathway in absence of ligand

regulation of muscle cell apoptotic process

negative regulation of anoikis

regulation of endothelial cell apoptotic process

negative regulation of extrinsic apoptotic signaling pathway

negative regulation of endothelial cell apoptotic process

negative regulation of extrinsic apoptotic signaling pathway via death domain receptors

extrinsic apoptotic signaling pathway in absence of ligand

intrinsic apoptotic signaling pathway by $\mathbf{5 3}$ class mediator

negative regulation of muscle cell apoptotic process

execution phase of apoptosis

negative regulation of striated muscle cell apoptotic process

regulation of lymphocyte apoptotic process

apoptotic DNA fragmentation

negative regulation of intrinsic apoptotic signaling patlwway

necrotic cell death

regulation of extrinsic apoptotic signaling pathway in absence of ligand

regulation of $T$ cell apoptotic process 
